\title{
Fosfat Kaplama İşleminde Aktivasyon Parametreleri ve Kaplama Süresinin Kaplama Kalitesine Etkisi
}

\author{
Elif Yaman $^{1 *}$, Semih Ulubayrak ${ }^{2}$, Nurgül Özbay ${ }^{3}$ \\ ${ }^{1}$ Bilecik Şeyh Edebali Üniversitesi, Merkezi Araştırma Laboratuvarı, Bilecik, Türkiye (ORCID: 0000-0002-1052-8779) elif.yaman@bilecik.edu.tr \\ ${ }^{2}$ Bilecik Şeyh Edebali Üniversitesi, Kimya Mühendisliği Bölümü, Bilecik, Türkiye (ORCID: 0000-0003-0474-8318) semihulubayrak@uzmankataforez.com \\ ${ }^{3}$ Bilecik Şeyh Edebali Üniversitesi, Kimya Mühendisliği Bölümü, Bilecik. Türkiye (ORCID: 0000-0002-0666-3417) nurgul.ozbay@bilecik.edu.tr
}

(İlk Geliş Tarihi 28 Kasım 2020 ve Kabul Tarihi 31 Ocak 2021)

(DOI: $10.31590 /$ ejosat.832850)

\begin{abstract}
ATIF/REFERENCE: Yaman, E., Ulubayrak, S., \& Özbay, N. (2021). Fosfat Kaplama İşleminde Aktivasyon Parametreleri ve Kaplama Süresinin Kaplama Kalitesine Etkisi. Avrupa Bilim ve Teknoloji Dergisi, (21), 629-634.

$\ddot{O} \mathbf{z}$

Metal sektöründe önemli bir problem olan korozyonun sebep olduğu malzeme ve iş gücü kaybına çözüm olarak yüzyıllardır uygulanan yöntemlerin en bilineni metal kaplama işlemidir. Fosfat kaplama, çok geniş bir kullanım alanına sahip olduğu için sıklıkla tercih edilen bir kaplama türüdür. Yapılan bu çalışmada, fosfat kaplama işlemi sırasındaki aktivasyon basamağı ve kaplama süresinin kaplama kalitesi üzerine etkisi incelenmiştir. Fosfat kaplama sırasındaki aktivasyon işleminde süreç parametresi olarak ortamın pH değeri, aktivasyon süresi ve fosfat kaplama süresi değiştirilmiştir. Elde edilen SEM görüntülerine göre aktivasyon ortamının pH değeri azaldıkça, fosfat kristal oluşumu kötü yönde etkilenmiş ve fosfat kaplama yüzeyinde lekeli bir görüntü elde edilmiştir. Yüksek pH değerlerinde ise metal yüzeyinde homojen olmayan fosfat tabakası oluştuğu belirlenmiştir. Aktivasyon süresinin düşük olduğu çalışmalarda parça yüzeyinin yeterince aktive olmadığı ve fosfat kaplama tabakasının güçlü tutunma sağlamayacağı belirlenmiş ve elde edilen SEM görüntülerine göre, aktivasyon maruziyeti için en uygun $\mathrm{pH}$ değerinin 9,00 ve aktivasyon süresinin $60 \mathrm{~s}$ olduğu belirlenmiştir.
\end{abstract}

Anahtar Kelimeler: Metal, Korozyon, Fosfat Kaplama, Otomotiv, Taramalı Elektron Mikroskobu, Aktivasyon

\section{Effect of activation parameters and coating time on the coating quality in phosphate coating process}

\begin{abstract}
Metal coating is the most well-known method that has been applied for centuries as a solution to material and labor loss caused by corrosion, which is an important problem in the metal industry. Phosphate coating is a preferred coating process because it has a wide range of uses. In this study, the effect of the activation step and coating time on the coating quality during the phosphate coating process was investigated. During activation process in phosphate coating, $\mathrm{pH}$ value of the solution, activation time and phosphate coating time have been changed as process parameters. According to the obtained SEM images, as the $\mathrm{pH}$ value of the activation solution decreased, the phosphate crystal formation has been adversely affected and a stained surface has been obtained on the phosphate coating surface. At high $\mathrm{pH}$ values, it has been determined that a heterogeneous phosphate layer formed on the metal surface. In studies with low activation time, it has been observed that the surface of the samples has not been activated enough and the phosphate coating layer would not provide strong adhesion, and according to the SEM images obtained, it was determined that the optimum $\mathrm{pH}$ value for the activation process was 9.00 and the activation time was $60 \mathrm{~s}$.
\end{abstract}

Keywords: Metal, Corrosion, Phosphate Coating, Automotive, Scanning Electron Microscopy, Activation

\footnotetext{
* Sorumlu Yazar: Bilecik Şeyh Edebali Üniversitesi, Merkezi Araştırma Laboratuvarı, Bilecik, Türkiye, ORCID: 0000-0002-1052-8779, elif.yaman@bilecik.edu.tr
} 


\section{Giriş}

Tüm endüstriyel alanlarda metal kullanımının günden güne artmasına bağlı olarak, metalin korunması ve kullanım ömrünün iyileştirilmesine yönelik çalışmalar da önem kazanmaktadır (Campbell, 2008; Sinha ve Tyagi, 2020).

Metalik malzemelerin içinde bulundukları mevcut çevre ile girdikleri elektrokimyasal reaksiyonlar sonucunda kimyasal yapısında ve yüzeyinde görülen değişiklikler korozyon olarak adlandırılır. Korozyonun meydana geldiği ortamlar genel olarak nemli hava, tuzlu su, asidik veya bazik ortam, alkalin ortam ve kirli havadır. Korozyonun sebep olduğu malzeme ve iş gücü kaybına çözüm olarak yüzyıllardır uygulanan yöntemlerin en bilineni metal kaplama işlemidir (Kakani ve Kakani, 2004; Deepak vd., 2019).

Metal kaplama uygulamalarında fiziksel, mekanik ve kimyasal yöntemler kullanılabilir. Endüstriyel anlamda en çok kullanılan kaplama çeşitleri galvaniz kaplama (Ageeva vd., 2020), çinko kaplama (Polyavok vd., 2020), krom kaplama (Podgornik vd., 2018; Öz vd., 2019), fosfat kaplama (Kollias vd., 2019), kalay kaplama (Cao vd., 2020) veya alüminyum (Guo vd., 2020) kaplamadır. Son yıllarda korozyon dayanımı için çinko lamelli kaplamalar da kullanılmaya başlanmıştır (Vu, 2012; Nardeli vd., 2020).
Fosfat kaplama, bir metal ile bir kimyasal çözeltinin reaksiyonu sonucu oluşur. Fosfat kaplamanın kompozisyonu, uygulama metoduna (sprey veya daldırma), banyonun karıştırılma derecesine, banyo kimyasal çeşitlerine, hızlandırıcının kalitesine ve diğer metal iyonlarının varlığına bağlı olarak değişmektedir (Ulubayrak, 2021). Demir fosfat, çinko fosfat ve mangan fosfat kullanılarak üç farklı şekilde uygulanabilir (Berk, 2004).

Fosfat kaplamanın uygulama alanları arasında boya ve polimer film kaplamalarla birlikte uygulanarak metal parçaların korozyondan korunması bulunmaktadır. Ayrıca, tel çekme, boru çekme, derin çekme gibi soğuk şekillendirme işlemlerinde koruyucu yağ ve vakslarla birlikte metallerin korozyondan korunması, yapışmayı arttırmak için kauçuk sektöründe kullanılması ve son işlem uygulanmadan korozyon koruması gibi işlemler de fosfat kaplamanın uygulama alanları arasında yer almaktadır. Fosfat kaplamanın kullanım amaçları ise, fosfat sonrasında uygulanacak olan boya ve organik tabakanın homojen olarak yayılmasını sağlamak için yüzeyi temizleyerek yüzeyi boyaya hazırlamak, metalin korozyon direncini arttırmak, alüminyum ve galvaniz gibi yapışma problemi olan yüzeylerde boyanın daha iyi tutunmasını sağlamak, boyanın darbe direncini ve esnekliğini artırmak ve suyun metal yüzeyine difüzyonunu engellemek olarak siralanabilir (Zimmermann vd., 2003).

Fosfat kaplama süreci aktivasyon, fosfat kaplama, durulama ve kürlenme basamaklarını içermektedir (Şekil 1).

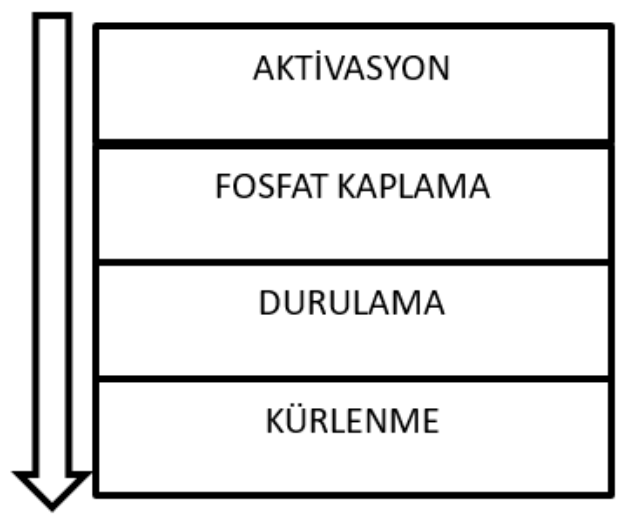

Şekil 1. Fosfat Kaplama Süreci

Fosfat kaplama işlemi öncesi uygulanan aktivasyonun amacı; kaplama sırasında korozyon direncini ve yapışma özelliklerini artıracak ince kristal yapıyı elde etmek için metali aktive etmektir. Aktivasyon basamağında durulama kullanılmiyorsa, fosfat kristal boyutu büyük olabilir ve bu durum fosfat kaplama yapısında boşluk oluşumuna neden olur. Büyük boşlukların korozyon oluşumuna sebep olmasından dolayı, kristal yapının her zaman $10 \mu \mathrm{m}$ 'den daha düşük olması tercih edilir. (Zimmermann vd., 2003).

Yapılan bu çalışmada, çinko lamelli kaplama işleminde alternatif yüzey temizliği olarak fosfat kaplamanın kullanılabilirliği ve fosfat kaplamanın aşamalarından biri olan aktivasyon basamağında, aktivasyon süresi ve pH'ının yanı sıra fosfat kaplama süresinin de kaplama kalitesi üzerine etkisi incelenmiştir.

\section{Materyal ve Metot}

Fosfat kaplama sırasındaki aktivasyon işleminde süreç parametresi olarak ortamın $\mathrm{pH}$ değeri ve aktivasyon süresi değiştirilmiştir. $1500 \mathrm{~L}$ su doldurulan banyoya aktifleştirici olarak 4 kg GARDOLENE V 6513 ilave edilip, banyo hacmi suyla 2000 L'ye tamamlanmıştır. Aktivasyon $\mathrm{pH}$ değerinin kaplama kalitesine etkisini belirlemek için, aktivasyon süresi 60 saniye olarak sabit tutulmuş ve $\mathrm{pH} 8,50,8,75,9,00,9,25$, 9,50 ve 10,00 olarak değiştirilmiştir (Tablo 1).

Aktivasyon süresinin kaplama kalitesine etkisini belirlemek için ise, yapılan çalışmalarda aktivasyon banyosunun $\mathrm{pH}$ değeri 9,00 olarak sabit tutulurken aktivasyon süresi $15,30,45$ ve 60 s olarak değiştirilmiştir (Tablo 2). 
Tablo 1. Aktivasyon $p H^{\prime} \iota$ denemeleri çalışma parametreleri

\begin{tabular}{ccccccc}
\hline & Deneme I & Deneme II & Deneme III & Deneme IV & Deneme V & Deneme VI \\
\hline Aktivasyon pH & 8,50 & 8,75 & 9,00 & 9,25 & 9,50 & 10,00 \\
Aktivasyon süresi (s) & 60 & 60 & 60 & 60 & 60 & 60 \\
Kaplama Süresi (dk) & 8 & 8 & 8 & 8 & 8 & 8 \\
\hline
\end{tabular}

Tablo 2. Aktivasyon süresi denemeleri çalışma parametreleri

\begin{tabular}{lcccc}
\hline & Deneme I & Deneme II & Deneme III & Deneme IV \\
\hline Aktivasyon süresi (s) & 15 & 30 & 45 & 60 \\
Aktivasyon $\mathrm{pH}$ & 9,00 & 9,00 & 9,00 & 9,00 \\
Kaplama Süresi (dk) & 8 & 8 & 8 & 8 \\
\hline
\end{tabular}

Yapılan deneysel çalışmalar sırasında fosfat banyosunun sahip olması gereken kimyasal özelliklerin teorik değerleri ve deneyler sırasında ölçülen bu değerler Tablo 3 'te verilmiştir. Fosfat kaplama süresinin kaplama kalitesine etkisini belirlemek için yapılan çalışmalarda ise kaplama süresi $3,5,8$ ve $10 \mathrm{dk}$ olarak değiştirilmiştir (Tablo 4).
Değiştirilen parametrelerin kaplama kalitesi üzerine etkisi elde edilen örneklerin yüzey görüntülerinin taramalı elektron mikroskobu (SEM) (HITACHI, TM-1000) ile alınmasiyla incelenmiştir. Örneklere uygulanan taramalı elektron mikroskobu analizlerinde, 1000x-3000x büyütme oranları kullanılmıştır. Ayrıca örneklerin kaplama kalınlıkları endüstriyel kaplama kalınlığı ölçüm cihazı (ELCOMETER 456) ile ölçülmüştür.

Tablo 3. Fosfat banyosu parametreleri

\begin{tabular}{lcc}
\hline & Teorik Değer & Ölçüm \\
\hline Toplam Asit & $17-25$ & 22,2 \\
Çinko Oranı $(\mathrm{g} / \mathrm{L})$ & $0,6-1,1$ & 1,01 \\
Nikel Oranı $(\mathrm{g} / \mathrm{L})$ & $0,6-1,2$ & 0,98 \\
\hline
\end{tabular}

Tablo 4. Fosfat kaplama süresi çalı̧̧ma parametreleri

\begin{tabular}{lcccc}
\hline & Deneme I & Deneme II & Deneme III & Deneme IV \\
\hline Kaplama Süresi (dk) & 3 & 5 & 8 & 10 \\
Aktivasyon süresi (s) & 60 & 60 & 60 & 60 \\
Aktivasyon pH & 9,00 & 9,00 & 9,00 & 9,00 \\
\hline
\end{tabular}

\section{Araştırma Sonuçları ve Tartışma}

Fosfat kaplama aşamalarından biri olan aktivasyon işleminde, aktivasyon banyosu $\mathrm{pH}$ değerinin değiştirilmesiyle elde edilen metal örneklerin yüzey görüntüleri Şekil 2'de verilmiştir. $\mathrm{pH}$ değerinin 8,75 ve 9,50 arasında olduğu durumda aktivasyon işleminin fosfat kaplama öncesi parça yüzeyini aktive ettiği belirlenmiştir.

Taramalı Elektron mikroskobu ile elde edilen görüntülere göre aktivasyon ortamının $\mathrm{pH}$ değeri azaldıkça, fosfat kristal oluşumu kötü yönde etkilenmiş ve fosfat kaplama yüzeyinde lekeli bir görüntü elde edilmiştir. Yüksek $\mathrm{pH}$ değerlerinde ise metal yüzeyinde homojen olmayan fosfat tabakası oluştuğu görülmüştür. En uygun $\mathrm{pH}$ değerinin 9,00 ve 9,25 olduğu belirlenmiş ve aktivasyon süresinin etkisinin belirlenmesi için gerçekleştirilen deneysel çalışmalarda $\mathrm{pH}$ değeri 9,00 olarak sabit tutulmuştur.
Aktivasyon süresinin kaplama kalitesi üzerine etkisinin belirlenmesi için yapılan çalışmalardan elde edilen SEM görüntüleri Şekil 3'te verilmiştir.

15 s aktivasyon uygulanan parçalarda kristaller arası boşluğun oldukça fazla olduğu görülmektedir. $30 \mathrm{~s}$ aktive edilmiş yüzeyde homojen yüzey dağglımının olmadığı ve aktive edilemeyen bölgenin lekeli bir görünüme sahip olduğu görülmektedir (Şekil 3(b)). Aktivasyon süresinin düşük olduğu denemelerde parça yüzeyinin yeterince aktive olmadığı ve fosfat kaplama tabakasının güçlü tutunma sağlamayacağı sonucuna varılmıştır. Elde edilen SEM görüntülerine göre, aktivasyon maruziyeti için en uygun $\mathrm{pH}$ değerinin 9,00 ve aktivasyon süresinin $60 \mathrm{~s}$ olduğu belirlenmiştir.

Fosfat kaplama süresinin kaplama kalitesi üzerine etkisinin belirlenmesi için yapılan çalışmalarda pH 9,00 olan aktivasyon banyosunda $60 \mathrm{~s}$ yüzeyi aktive edilmiş parçalar $3,5,8$ ve $10 \mathrm{dk}$ fosfat banyosunda tutulmuştur (Şekil 4). 

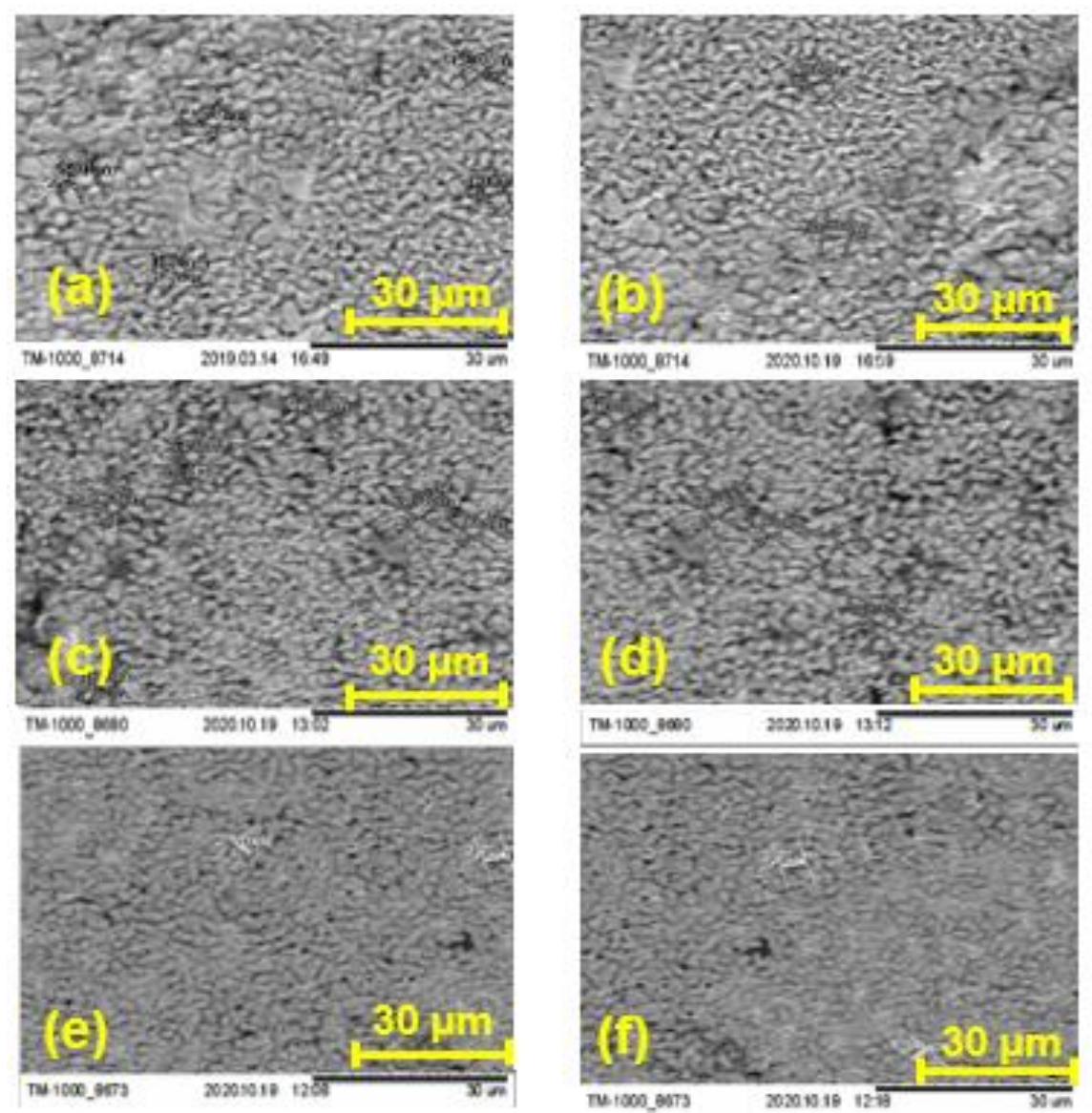

Şekil 2. Farklı pH değerlerinde elde edilen metal yüzeylerin SEM görüntüleri

(a) $\mathrm{pH} 8,5$ (b) $\mathrm{pH} 8,75$ (c) $\mathrm{pH} 9,00$ (d) $\mathrm{pH} 9,25$ (e) $\mathrm{pH} 9,50$ (f) $\mathrm{pH} 10,00$

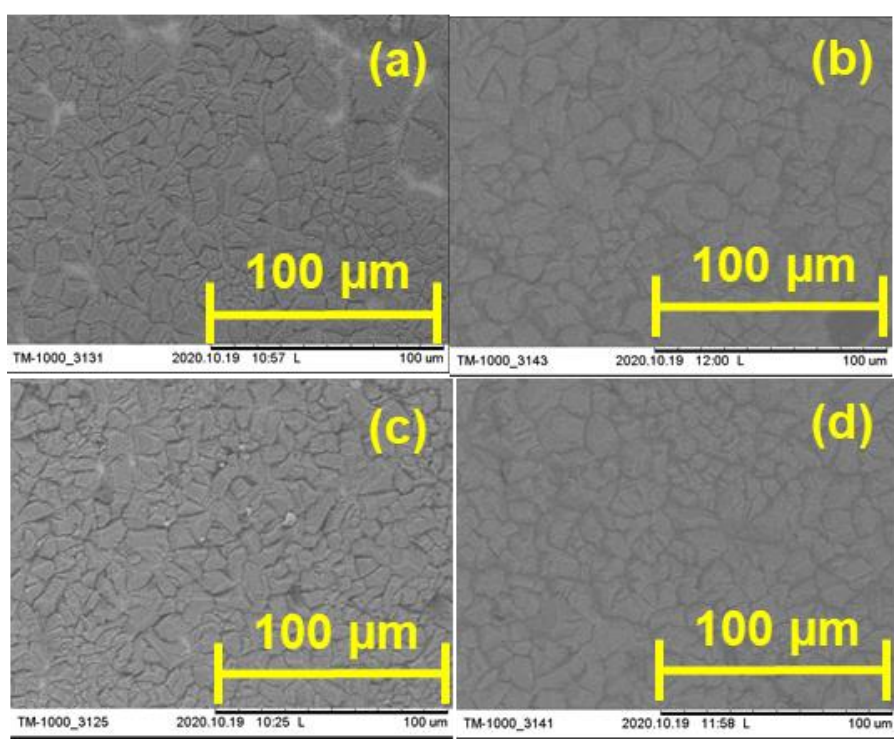

Şekil 3. Farklı aktivasyon süresi değerlerinde elde edilen metal yüzeylerin SEM görüntüleri (a) $15 \mathrm{~s}$ (b) $30 \mathrm{~s}$ (c) $45 \mathrm{~s}$ (d) $60 \mathrm{~s}$
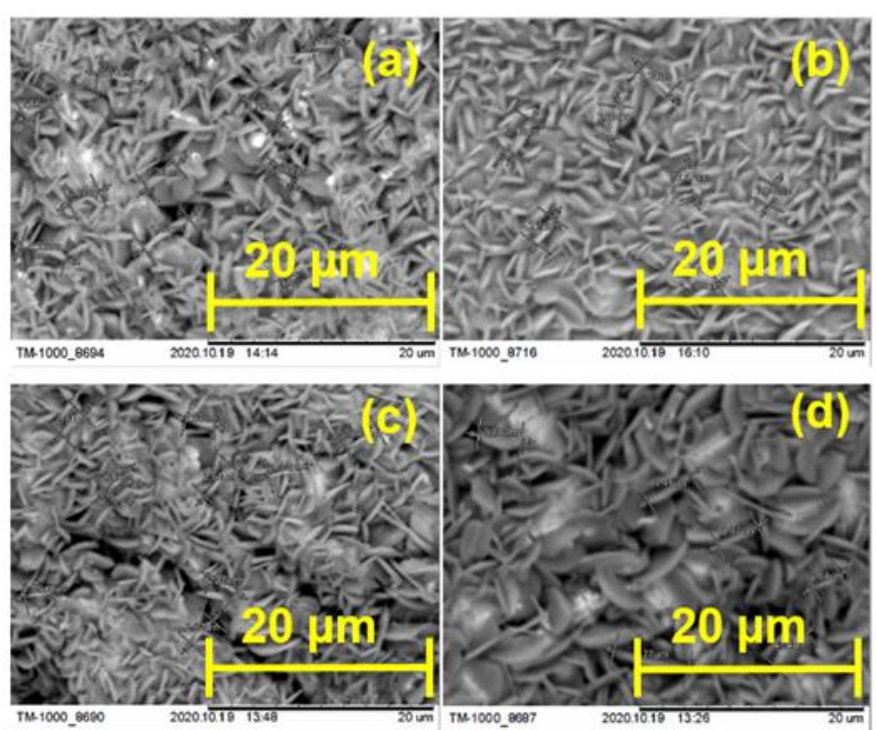

Şekil 4. Farklı fosfat kaplama sürelerinde elde edilen metal yüzeylerin SEM görüntüleri (a) $3 \mathrm{dk}$ (b) $5 \mathrm{dk}$ (c) $8 \mathrm{dk}$ (d) $10 \mathrm{dk}$ 
Fosfat kaplama süresinin her seviyesinde aktifleşmiş yüzeye tutunmanın gerçekleştiği görülmüş fakat düşük sürelerde fosfat kaplanan parçaların kaplama kalınlığının daha ince olduğu gözlemlenmiş̦tir (Şekil 5 ve Tablo 5).

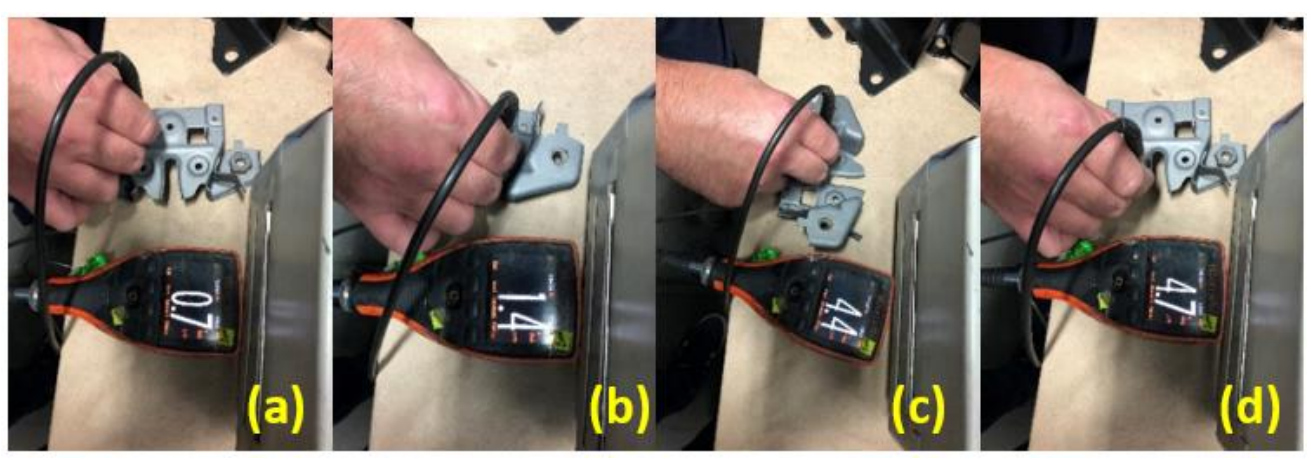

Şekil 5. Kaplama kalınlıkları (a) $3 \mathrm{dk}$ (b) $5 \mathrm{dk}$ (c) $8 \mathrm{dk}$ ve (d)10 dk

Tablo 5. Fosfat kaplama süresinin kaplama kalınlıklarına etkisi

\begin{tabular}{lcccc}
\hline & Deneme I & Deneme II & Deneme III & Deneme IV \\
\hline Kaplama Süresi (dk) & 3 & 5 & 8 & 10 \\
Kaplama kalınlıkları (mm) & 0,7 & 1,4 & 4,4 & 4,7 \\
\hline
\end{tabular}

\section{Sonuç}

Yapılan deneysel çalışmalar sonucunda elde edilen örneklerin yüzey görüntüleri incelendiğinde, metal parçalara fosfat kaplama işlemi öncesinde uygulanan aktivasyonun $\mathrm{pH}$ değeri düşük iken kristal yapının kötü yönde etkilendiği ve lekeli bir fosfat tabakası elde edildiği belirlenmiştir. Aynı zamanda yüksek $\mathrm{pH}$ değerlerinde metalin kaplama öncesi aktifleştiği fakat homojen dağılımı olmayan bir fosfat kristal yapısı elde edildiği görülmüştür.

Doğru $\mathrm{pH}$ aralığında aktivasyon süresi kısaldığında (15 s ve $30 \mathrm{~s}$ ) kristaller arası boşluğun fazla olduğu, dolayısıyla fosfat kaplamanın metal yüzeye iyi seviyede tutunmayacağ1 gözlenmiştir. Fosfat kaplama süresinin kaplama kalitesi üzerine etkisinin belirlenmesi için yapılan çalışmalarda, kaplama süresinin her seviyesinde aktifleşmiş yüzeye tutunmanın gerçekleştiği görülmüş fakat düşük sürelerde fosfat kaplanan parçaların kaplama kalınlığının daha ince olduğu belirlenmiştir. Deneysel sonuçlara göre en iyi kaplama özellikleri aktivasyon banyosu $\mathrm{pH}$ değerinin 9.00, aktivasyon süresinin $60 \mathrm{~s}$ ve fosfat kaplama süresinin ise $10 \mathrm{dk}$ olduğu koşullarda elde edilmiştir.

\section{Kaynakça}

Ageeva, E., Latipov, R., \& Altukhov, A. (2020). Dimensional characteristics of wear-resistant electroerosive titaniumtungsten-cobalt powders for galvanic coatings. Materials Today: Proceedings.

Berk, V. (2004) Yüzey işlem teknolojileri 1.

Campbell, F. C. (Ed.). (2008). Elements of metallurgy and engineering alloys. ASM International.

Cao, X., He, W., Liao, B., He, G., Jiao, Y., Huang, D., \& Wang, S. (2020). Effect of TiN/Ti coating combined with laser shock peening pre-treatment on the fatigue strength of Ti6Al-4V titanium alloy. Surface and Coatings Technology, 403, 126393.

Guo, F., Jiang, W., Tang, G., Xie, Z., Dai, H., Wang, E., ... \& Liu, L. (2020). Enhancing anti-wear and anti-corrosion performance of cold spraying aluminum coating by high current pulsed electron beam irradiation. Vacuum, 182, 109772.

Kollias, K., Mylona, E., Adam, K., Chrysochoou, M., Papassiopi, N., \& Xenidis, A. (2019). Characterization of phosphate coating formed on pyrite surface to prevent oxidation. Applied Geochemistry, 110, 104435.

Deepak, J. R., Raja, V. B., \& Kaliaraj, G. S. (2019). Mechanical and corrosion behavior of $\mathrm{Cu}, \mathrm{Cr}, \mathrm{Ni}$ and $\mathrm{Zn}$ electroplating on corten A588 steel for scope for betterment in ambient construction applications. Results in Physics, 14, 102437.

Kakani, S., \& Kakani, A. (2004). Material Science. sl: New Age International Ltd.

Nardeli, J. V., Fugivara, C. S., Taryba, M., Montemor, M. F., \& Benedetti, A. V. (2020). Biobased self-healing polyurethane coating with $\mathrm{Zn}$ micro-flakes for corrosion protection of AA7475. Chemical Engineering Journal, 404, 126478.

Öz, A., Demir, A., Sağıroğlu, S., \& Yakut, A. K. (2019). Plazma Sprey Tekniği ile Cr2O3 Kaplanmış Fren Diskinin Frenleme Performansının Deneysel Olarak İncelenmesi. Avrupa Bilim ve Teknoloji Dergisi, (15), 394-403.

Podgornik, B., Massler, O., Kafexhiu, F., \& Sedlacek, M. (2018). Crack density and tribological performance of hard-chrome coatings. Tribology International, 121, 333340.

Polyakov, N. A., Botryakova, I. G., Glukhov, V. G., Red'kina, G. V., \& Kuznetsov, Y. I. (2020). Formation and anticorrosion properties of superhydrophobic zinc coatings on steel. Chemical Engineering Journal, 127775. 
Sinha, M., \& Tyagi, R. K. (2020). Strength and corrosion analysis in alloy steel and E-glass composite wear ring in automotive engine cooling water pump. Materials Today: Proceedings, 21, 1474-1478.

Ulubayrak, S. (2021). Metal Parçalar Üzerine Fosfat ve Su Bazlı Lamelli Kaplama Araştırılması. Yüksek Lisans Tezi, Bilecik Şeyh Edebali Üniversitesi Anadolu Üniversitesi Ortak Programı, Fen Bilimleri Enstitüsü Kimya Mühendisliği Anabilim Dalı.

Zimmermann, D., Munoz, A. G., Schultze, J. W. (2003). Microscopic local elements in the phosphating process. Electrochimica acta, 48(20-22), 3267-3277.

$\mathrm{Vu}$, T.N. (2012). Selective dissolution from Zn-Al alloy coatings on steel (Doctoral dissertation, Université Pierre et Marie Curie-Paris VI). 